\title{
PREPARATION DIFFERENTIAL CULTURE MEDIUM FOR CRYPTOCOCCUS NEOFORMANS FROM AQUEOUS EXTRACT OF LEAVES AND FLOWERS OF CHRYSANTHEMUM CINERARIAEFOLIUM
}

\author{
NEERAN OBIED JASIM ${ }^{1 *}$, NOOR DAKEL MEHDI ${ }^{2}$ \\ ${ }^{1}$ Department of Clinical Laboratory Sciences, College of Pharmacy, University of AL-Qadisiyah, Iraq. ${ }^{2}$ Department of Biology, College of \\ Science, University of AL-Qadisiyah, Iraq. Email: neeranjasim@gmail.com
}

Received: 24 April 2019, Revised and Accepted: 20 December 2019

\section{ABSTRACT}

Objective: A new medium was prepared to isolate and diagnose the yeast Cryptococcus neoformans from flower and leaves aqueous extract of chrysanthemum.

Methods: Prepared differential culture medium for C. neoformans from aqueous extract of leaves and flowers of Chrysanthemum cinerariaefolium and chemical, spectral tests of the extracts were tested, in addition of gas chromatography (GC)-mass was used to diagnose phenolic compounds in both leaves and flowers.

Results: Showed that the yeast was grow with typical colonies on the new medium compared with other media which using in diagnosed of this yeast such as Staib agar and Sabourauds dextrose agar and unlike the yeast Candida albicans (as a negative control), which appeared in cream to white on this medium. Furthermore, the colonies are dark brown in color on flower chrysanthemum medium and light brown color on leaves chrysanthemum medium. In addition, the results of the chemical and spectral tests of the extracts confirmed that the plant contains many active compounds such as alkaloids, turbines, tannins, and phenols. The analysis of the extracts of phenolic compounds using GC-mass led to the diagnosis of five compounds in the leaf extract and nine compounds in the flower extract of this plant.

Conclusions: The media was prepared is differential medium that use to diagnosis of Cryptococcus such as Staib agar. Moreover, low economic cost, which consists of leaves and flowers of a plant available, abundance and the method of preparation is very simple.

Keywords: Cryptococcus neoformans, Fungi, Aqueous Extract, Chrysanthemum cinerariaefolium, Differential medium.

(c) 2020 The Authors. Published by Innovare Academic Sciences Pvt Ltd. This is an open access article under the CC BY license (http://creativecommons. org/licenses/by/4. 0/) DOI: http://dx.doi.org/10.22159/ajpcr.2020.v13i2.33723

\section{INTRODUCTION}

Cryptococcus neoformans are the most widespread opportunistic fungi in the world affecting humans and most animals [1]. The genus Cryptococcus belongs to yeast-like, an opportunistic yeast that affects immunocompromised people, which causes high morbidity and mortality, and also affects people who are immunocompetent [2]. Genus Cryptococcus contains more than 100 species classified according to the modern classification [3], but the pathogens of humans and animals are very few. The most important are C. neoformans and Cryptococcus gattii. But Cryptococcus albidus and Cryptococcus laurentii, are rarely cause disease [4]. C. neoformans have four serotypes based on the antigenic properties of it (A, B, C, and D) [5]. Serotype A is the most common type and responsible for the greater proportion of cases of cryptococcosis [6]. The yeast is characterized by spherical to elliptic diameter (6-4) $\mathrm{mm}$, surrounded by a thick capsule of polysaccharides (1-30 $\mu$ ). Reproduction by budding (a single bud of the base, not true hyphae) and no germ tube [7]. C. neoformans cause cryptococcosis, a globally dangerous disease [8]. This disease is more severe in people with immunosuppressive weakness, especially those with T-cell (CD4) cellmediated immunity and people with human immunodeficiency virus [9]. As well as in healthy people, but in small numbers, almost $95 \%$ of cases occur in middle- and low-income countries [10]. Yeast grows on the Sabouraud dextrose agar (SDA) in colonies of creamy, smooth, and mucous form. When the yeast grows on Staib agar, it is formed in spherical, brown, and mucous shaped colonies. The brown color is due to the yeast of the phenoloxidase enzyme, which oxidizes the phenolic compounds found in the plant medium; precipitation of the melanin pigments on the yeast cell gives it brown colonies. Therefore, we used in this study plant (at this $1^{\text {st }}$ time) which contains phenolic compounds in prepared differential medium for this yeast.

\section{METHODS}

SDA: Use this medium for comparison and, prepared according to the method of Odds, 1991, melted $65 \mathrm{~g}$ of SDA in $1000 \mathrm{~mL}$ of distilled water.

Staib agar medium: Used for comparison and prepared according to the method Staib et al. [11] by dissolving the following materials:

Black seed niger seed $50 \mathrm{~g}$ (obtained from herbal medicine stores in local markets)

- Glucose: $1 \mathrm{~g}$

- Creatinine: $1 \mathrm{~g}$

- $\mathrm{KH}_{2} \mathrm{PO}_{4}: 1 \mathrm{~g}$

- Agar: $15 \mathrm{~g}$

- D.W.: $1000 \mathrm{ml}$.

Chrysanthemum flower agar: Prepared at the $1^{\text {st }}$ time from available and simple materials:

- Chrysanthemum (Chrysanthemum cinerariaefolium) flower: $50 \mathrm{~g}$

- Glucose: $1 \mathrm{~g}$

- Agar: $15 \mathrm{~g}$

- D.W.: $1000 \mathrm{ml}$.

Chrysanthemum leaves agar: Prepared at the $1^{\text {st }}$ time from available and simple materials:

- Chrysanthemum (C. cinerariaefolium) leaves: $50 \mathrm{~g}$

- Glucose: $1 \mathrm{~g}$

- Agar: $15 \mathrm{~g}$

- D.W.: $1000 \mathrm{ml}$.

Fungal strain

C. neoformans and Candida albicans isolates were obtained from the Micro. Laboratory, Department of Life Sciences, Faculty of Science/ 
University of Al-Qadisiyah. These isolates were saved on slant of SDA until to use.

\section{Preparation of new media}

Prepared by a weight of $50 \mathrm{~g}$ ofdried flowers and leaves of $C$. cinerariaefolium separately and then added to one liter of distilled water and boiled for half an hour, then filtered through a medical gauze and complete the volume of the solution by distilled water to one liter and then add $1 \mathrm{~g}$ of glucose and $15 \mathrm{~g}$ of agar sterilized with autoclave. After sterilization, added chloramphenicol $(250 \mathrm{mg} / \mathrm{mL})$ and distributed in sterile dishes.

\section{Cultivation of fungal strain}

By streaking the isolates (that previously cultured on SDA at $37^{\circ} \mathrm{C}$ for $48 \mathrm{~h}$ ) on the each medium which was prepared from leaves and flowers media. C. albicans was also developed as a negative control. The isolates were also studied on the Staib agar and SDA as a positive control and incubated at $37^{\circ} \mathrm{C}$ for 7 days and any chromatic change of colonies was followed.

Analysis of the components of the leaves and flowers of C. cinerariaefolium

Preparation of water extract, not flowers and leaves of the C. cinerariaefolium

Prepare the water extract of the leaves and flowers by a weight of $20 \mathrm{~g}$ of crushed leaves and flowers separately in $200 \mathrm{ml}$ of distilled water and then put each in a stirrer incubator $120 \mathrm{rpm}$ and $50 \mathrm{~m}$ for $16 \mathrm{~h}$. Then, the extracts were filtered $100 \%$ (leaves and flowers) and were storage of extracts to be used [12].

Chemical detection of some active components of water extracts

Some chemical components were chemically detected using the following reagents [13] Table 1.

Extraction of phenolic compounds from the leaves and flowers of C. cinerariaefolium

Phenolic compounds were extracted according to the method was mentioned by $[13,14]$ :

- Mix $20 \mathrm{~g}$ of crushed leaves and flowers separately with $400 \mathrm{ml}$ of acetic acid solution (1\%).

- Extraction using the inverter condenser in water bath at a ËšC of $70 \mathrm{~m}$ for $8 \mathrm{~h}$. Then left to cool down.

- Filtered the mixture with a piece of gauze and then with the filter paper Whatman No. 1 and transfer to the funnel and add the same size of n-propanol and then the amount of salt (sodium chloride) until reaching saturation. It is composed of two layers, the upper and the organic layer containing the phenolic compounds, while the lower is eliminated.

- Propanial extract was collected and dried with rotary evaporator at a ËšC of $45 \mathrm{C}$ and then left to dry at room ËšC then collected the resulting material and kept for use.

\section{Spectral tests}

The ultraviolet (UV) and infrared spectra of phenolic compounds for both leaves and flowers were measured separately using the UV-visible spectrophotometer and Fourier transform infrared, respectively.

Table 1: Chemical components of water extracts

\begin{tabular}{|c|c|c|c|}
\hline No. & Compound & Reagents & Result \\
\hline 1. & Alkaloids & Tannic acid & $\begin{array}{l}\text { The appearance of } \\
\text { turbid white nailed }\end{array}$ \\
\hline 2. & Phenols & $\begin{array}{l}\text { Aqueous ferric } \\
\text { chloride }(1 \%)\end{array}$ & $\begin{array}{l}\text { Appearance of green } \\
\text { precipitation }\end{array}$ \\
\hline 3. & Turbines & Liebermann-Burchard & A brown ring \\
\hline 4. & Foam & Foam test & $\begin{array}{l}\text { Foam is dense over the } \\
\text { surface of the extract } \\
\text { and lasts long }\end{array}$ \\
\hline 5. & Tannins & $1 \%$ lead acetate & White deposit gelatinous \\
\hline
\end{tabular}

Diagnosis phenolic compounds

The gas chromatography (GC)-mass analysis was performed using a GC Clarus 500 PerkinElmer instrument with a mass spectrometer and a silica capillary column with dimensions of $30 \times 0.25 \times 1 \mu \mathrm{m}$. The carrier gas used is helium with a drop of $1 \mathrm{ml} / \mathrm{min}$. The injector is operated at $250^{\circ} \mathrm{C}$ and the oven was programmed at $110^{\circ} \mathrm{C}$ for two min and then gradually increased to $280^{\circ} \mathrm{C}$ in $9 \mathrm{~min}$. The components were determined based on the data of the National Institute of Technology, where the results were compared with the range of known components.

\section{RESULTS}

Growth on the developed media

The results showed that the yeast of $C$. neoformans was grown on the SDA at $37^{\circ} \mathrm{C}$ in white circular colonies and mucus smooth, as in Fig. 1, and these results are consistent with $[15,16]$. When the yeast of $C$. neoformans was grown on the Staib agar at $37^{\circ} \mathrm{C}$, the results showed that the yeast had grown in spherical colonies, smooth mucus, and brown structure. The browned $C$. neoformans were colored brown due to phenoloxidase (phenoloxidase), which oxidizes the phenolic compounds found in the medium, depositing the melanin pigment on the wall of the yeast, giving colonies of brown, and distinct colonies from C. albicans Fig. 2 .

\section{Analysis of the components of the leaves and flowers}

The results of the chemical extracts for the leaves and flowers of the plant (Table 2) showed that the extract contains phenolic compounds, tannins, and turbines.
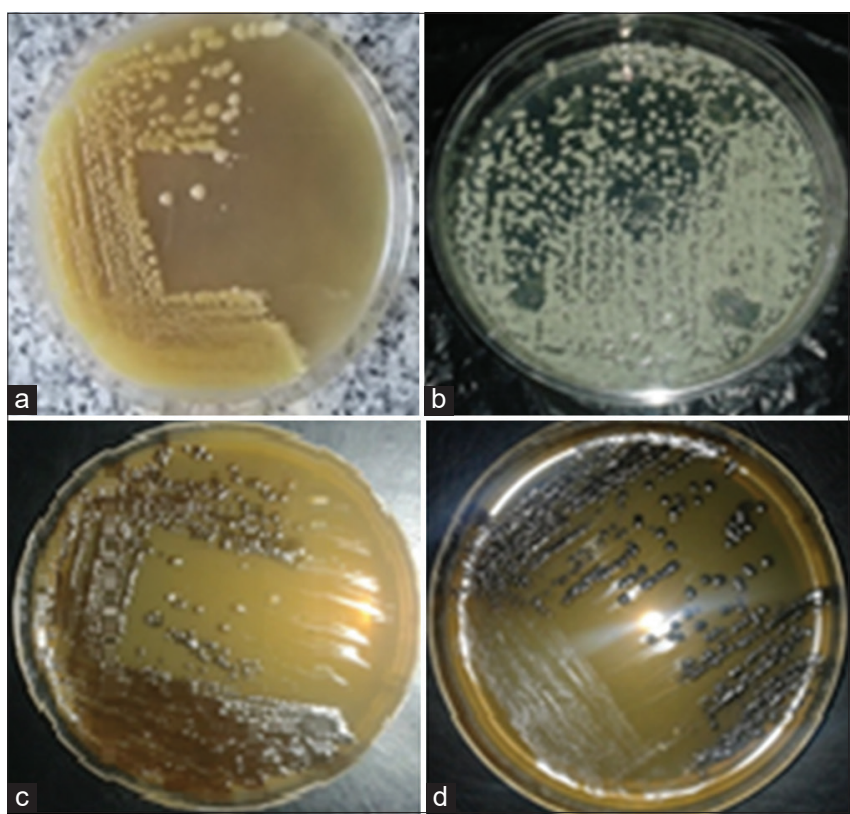

Fig. 1: Growth of Cryptococcus neoformans on various media, (a) Staib agar, (b) SDA, (c) leaves medium, (d) flower medium

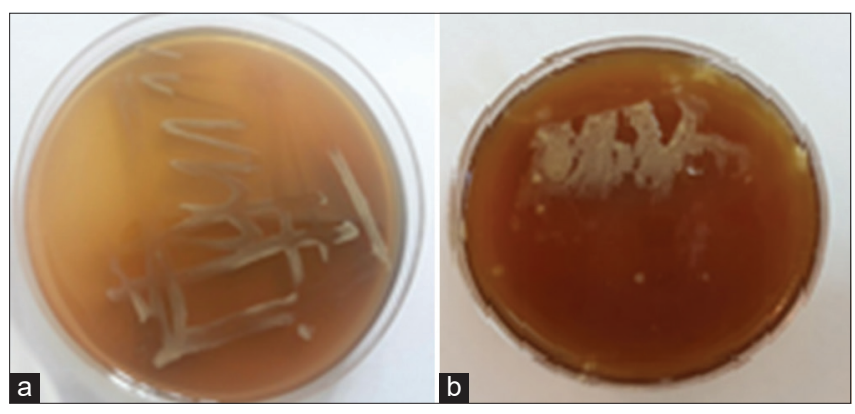

Fig. 2: Candida albicans (negative control) on the media (a) leaves, (b) flowers 
Spectral tests

Figs. 3 and 4 show the UV spectrum of the phenolic extract of both leaves and flowers, respectively. It is noted that there is a peak at $328 \mathrm{~nm}$. This is due to the hydroxyl group. The second beak was at $260 \mathrm{~nm}$. Advanced analysis in food strategies, which stated that $\lambda$ max for phenol lies between 211 and $270 \mathrm{~nm}$. While Figs. 5 and 6 represent the red-ray spectrum of the phenolic extract for each of the leaves and flowers of the plant, respectively. The figures show that there is a spectral frequency at 3811 in Fig. 5 and 3865 in Fig. 6 which belongs to the OH group. The frequencies at 2923 in Fig. 5 and 2931 in Fig. 6 refer to aromatic $\mathrm{CH}$ and frequencies at 1627 in the two forms; they belong to the double bonds of $(\mathrm{C}=\mathrm{C})$.

Table 2: Chemical tests of active compounds in the water extract of leaves and flowers of plant

\begin{tabular}{lllll}
\hline No. Compound & Reagent & \multicolumn{2}{c}{ Treatment } \\
\cline { 3 - 4 } & & & Leaves & Flower \\
\hline 1. & Alkaloids & Tannic acid & + & + \\
2. & Phenols & Aqueous ferric chloride $(1 \%)$ & + & + \\
3. & Turbines & Liebermann-Burchard & - & + \\
4. & Foam & Foam test & + & + \\
5. & Tannins & 1\% lead acetate & + & + \\
\hline
\end{tabular}

(+): Positive, (-): Negative

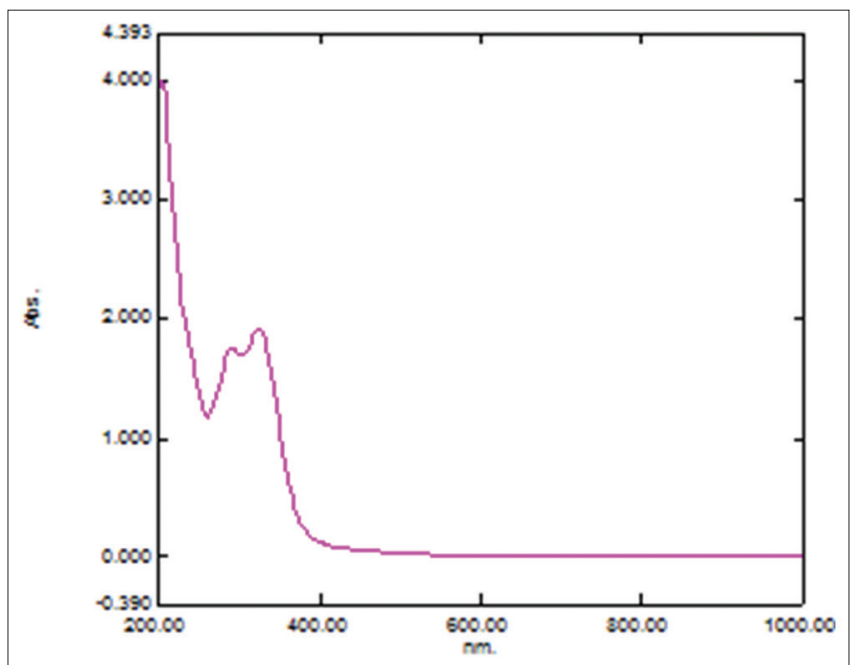

Fig. 3: Spectroscopy of the ultraviolet radiation of phenolic extract of flower

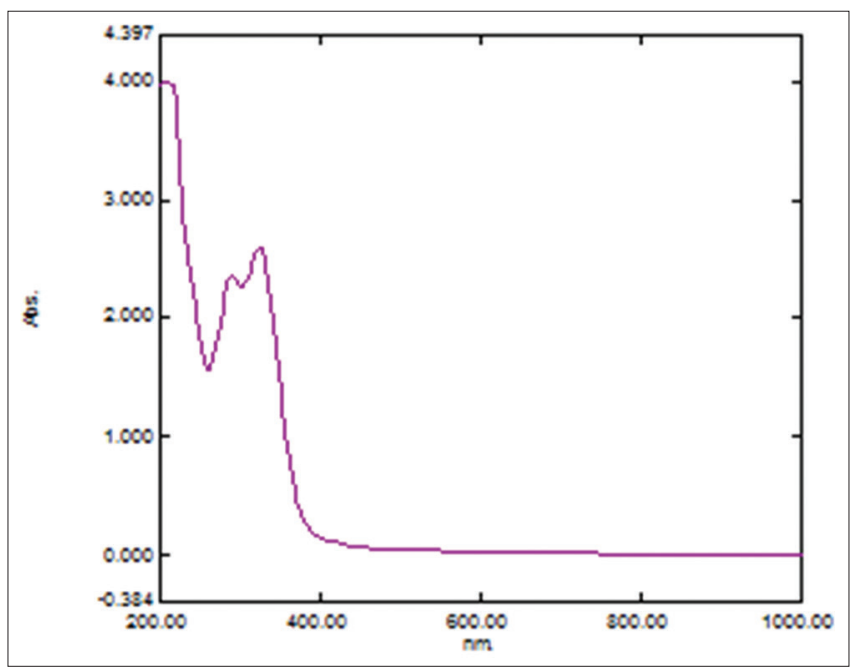

Fig. 4: Spectroscopy of the ultraviolet of the phenolic extract of leaves
Diagnosis of phenolic compounds using GC mass

Tables 3 and 4 and Figs. 7 and 8 show the results of the analysis using GC mass for the phenolic extract of the leaves and flowers of the plant, respectively. Extracts were found to contain a number of chemical compounds. Five compounds appeared in the leaves extract and nine compounds in the flower extract with some compounds present in both extracts but with a slightly different retention time.

\section{DISCUSSION}

The literature reported that high centration's from phenolic compounds in the leaves and flowers of Chrysanthemum morifolium, therefore colony of yeast appear with brown colour as a results of phenolic oxidation, these results are consistent with Lungran et al. [17]. The test of the ability of the yeast $C$. neoformans to grow on the new media of the flowers and leaves; the results showed that the yeast can grow easily and specifications of colonies typical of the above media and can be distinguished colonies easily by brown color, unlike the yeast $C$. albicans (as a negative control), which appeared in cream to white because the plant is a container of high concentrations of phenolic compounds, and the results showed that colonies of yeast growing on the medium of the flowers are dark brown compared with their colonies on the medium of leaves are light brown and can be attributed to the different concentrations of phenolic compounds between flowers and leaves. As shown in Fig. 1, the results are in line with Dulaimi et al., [18], Minhas et al. [19], Katiyar et al. [20], Ajah [21] of their use of media contained a phenolic compound. Plants are a potential source of new paradigms of antibiotics such as alkaloids, flavonoids, glycosides, terpenoids, and tannins [22]; results of active compounds appear the extracts contain many types of these compounds; this result is in line with Kareem and Amran [23]. Spectra test of both extracts shows phenolic compounds; our results are in coincidence

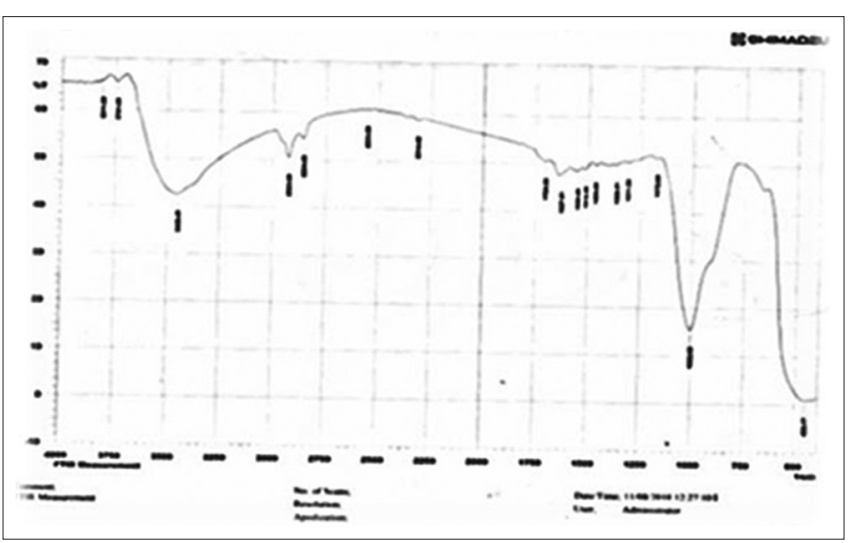

Fig. 5: Fourier-transform infrared spectrometry of phenolic extract of leaves

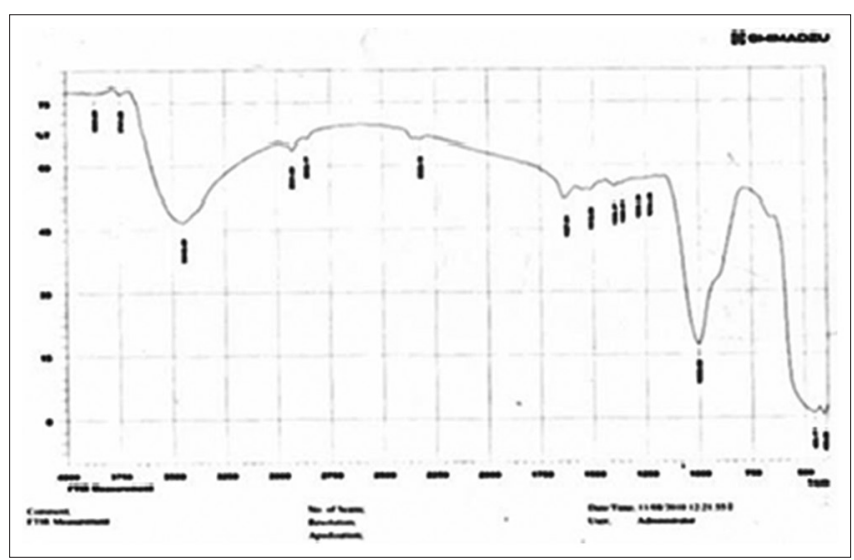

Fig. 6: Fourier-transform infrared spectrometry of phenolic extract of flowers 
Table 3: Chemical compounds in phenolic extract of leaves of plant

\begin{tabular}{lll}
\hline No. & Compound & Retention time \\
\hline 1. & Butanoic acid & 10.11 \\
2. & 3,7,11,15-tetramethyl-2-hexadecen -1-01 & 12.63 \\
3. & 2-(2-methylpropyl)- & 13.55 \\
4. & 3-Buten-2-one, & 18.48 \\
& 4-(2-hydroxy-2,6,6-trimethylcyclohexyl)- & \\
5. & Thujone & 23 \\
\hline
\end{tabular}

Table 4: Chemical compounds in phenolic extract of flowers of plant

\begin{tabular}{lll}
\hline No. & Compound & Retention time \\
\hline 1. & Acetic acid & 6.88 \\
2. & Chlorogenic acid & 9.50 \\
3. & 2-Butenic acid- & 10.50 \\
4. & Hexadecanol & 12.11 \\
5. & 3,7,11,15-tetramethyl-2-hexadecen -1-01 & 12.65 \\
6. & 3,6-octadien-1-01,3,7-dimethyl & 16.82 \\
7. & 3-Buten-2-one, & 18.40 \\
& 4-(2-hydroxy-2,6,6-trimethylcyclohexyl)- \\
8. & Thujone & 22.85 \\
9. & Luteolin-7- $\beta$-glucoside & 24.20 \\
\hline
\end{tabular}

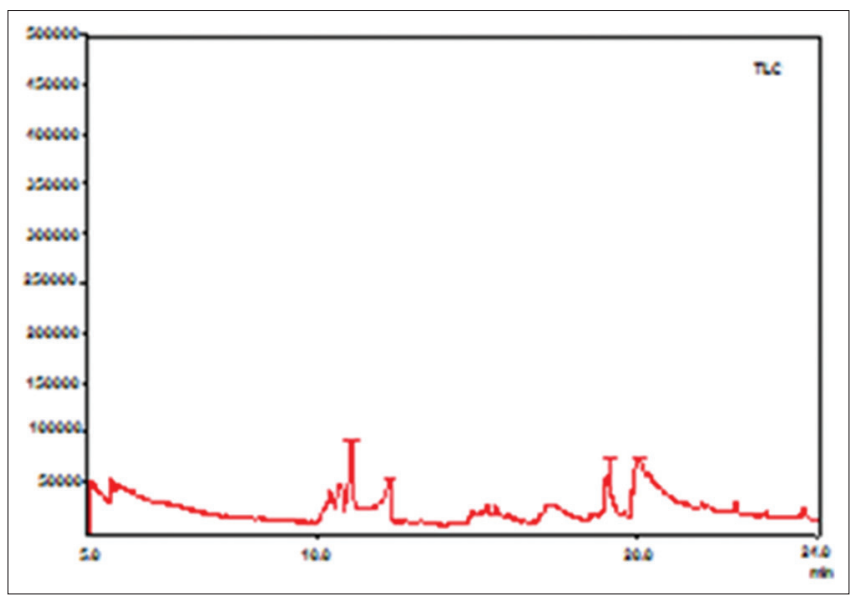

Fig. 7: Chromatogram for leaf extract

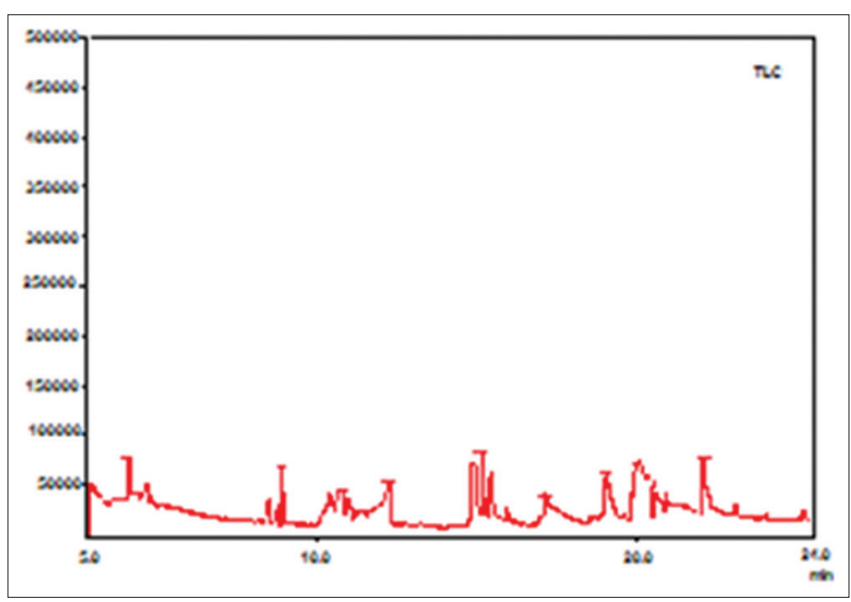

Fig. 8: Chromatogram for flower extract

with Silverstein et al. [24]. Gas chromatography-mass spectrometry used to identify different substances within a test sample such as plants sample [25] in this study GC-mass results appear that leaves and flowers of the plant were tested, rich with phenolic compounds this result is consistent with Han et al. [26] and Sheikh et al. [27].

\section{CONCLUSIONS}

This medium is characterized by low economic cost, which consists of leaves and flowers of a plant available, abundance and the method of preparation is very simple. It is similar to the medium of chrome agar of Candida in terms of containing the phenolic compounds, which acts as a color detector, which supports the presence of phenoloxidase enzyme and works to deposition of melanin giving dark brown color. Furthermore, the media were prepared which is progress of media that use to diagnosis of Cryptococcus such as Staib agar.

\section{ACKNOWLEDGMENT}

I would like to express my sincere gratitude to the members of the Laboratory of Bacteria at Al-Dewaniyah Teaching Hospital and Institute of Science and Technology for giving invaluable guidance, support, and help which made to me think and do this work.

\section{AUTHORS' CONTRIBUTIONS}

The author declares that this work was done by the author named in this article.

\section{CONFLICTS OF INTEREST}

There are no conflicts of interest we alone responsible for the content and writing of this article.

\section{FUNDING}

This research did not receive any specific grant from funding agencies.

\section{ETHICS STATEMENT}

No ethical approval was required as the research in this article related to microorganisms.

\section{REFERENCES}

1. Sidrim JJ, Costa AK, Cordeiro RA, Brilhante RS, Moura FE, Castelo-Branco DS, et al. Molecular methods for the diagnosis and characterization of Cryptococcus: A review. Can J Microbiol 2010;56:445-58

2. Chen J, Varma A, Diaz MR, Litvintseva AP, Wollenberg KK, KwonChung KJ. Cryptococcus neoformans strains and infection in apparently immunocompetent patients, China. Emerg Infect Dis 2008;14:755-62.

3. Fonseca A, Boekhout T, Fell JW. Cryptococcus Vuillemin. In: Kurtzman CP, Fell JW, Boekhout T, editors. The Yeasts, a Taxonomic study. $5^{\text {th }}$ ed. Amsterdam, Netherlands: Elsevier; 2011. p. 1661-738.

4. Baddley JW, Dismukes WE. Cryptococcosis. In: Dismukes WE, Pappas PG, Sobel JD, ediotrs. Clinical Mycology. Ch. 12. Oxford: Oxford University Press; 2003. p. 519.

5. Kwon-Chung KJ, Varma A. Do major species concepts support one, two or more species within Cryptococcus neoformans? FEMS Yeast Res 2006;6:574-87.

6. Vu K, Eigenheer RA, Phinney BS, Gelli A. Cryptococcus neoformans promotes its transmigration into the central nervous system by inducing molecular and cellular changes in brain endothelial cells. Infect Immun 2013;81:3139-47.

7. Koneman EW, Allen SD, Jawa WM, Sachreckeber PC. Color Atlas and Textbook of Diagnositic Microbiology. $4^{\text {th }}$ ed. Philadelphia, PA, United States: J.B. Lippincott; 1992. p. 838-55.

8. Barnett JA. A history of research on yeasts 14: Medical yeasts part 2, Cryptococcus neoformans. Yeast 2010;27:875-904.

9. Jarvis JN, Casazza JP, Stone HH, Meintjes G, Lawn SD, Levitz SM, et al. The phenotype of the Cryptococcus-specific CD4+ memory T-cell response is associated with disease severity and outcome in HIVassociated cryptococcal meningitis. J Infect Dis 2013;207:1817-28.

10. Leal AL, Faganello J, Fuentefria AM, Boldo JT, Bassanesi MC, Vainstein MH. Epidemiological profile of cryptococcal meningitis patients in Rio Grande do Sul, Brazil. Mycopathologia 2008;166:71-5.

11. Staib F, Seibold M, Antweiler E, Fröhlich B, Weber S, Blisse A. The brown colour effect (BCE) of Cryptococcus neoformans in the 
diagnosis, control and epidemiology of C. neoformans infections in AIDS patients. Zentralbl Bakteriol Mikrobiol Hyg A 1987;266:167-77.

12. Kalia R, Kaur J, Kaur A. Antitumor activity of aqueous extract of different cultivars of $C$. morifolium $\mathrm{R}$ using potato disc tumor assay. J Pharm Sci Res 2016;18:1262-5.

13. Harborn J. Phytochemical Method. $2^{\text {nd }}$ ed. New York: Chapman and Hall; 1984. p. 278.

14. Tiwari P, Kumar B, Kaur G, Kaur H. Phytochemical screening and extraction. A review. Int Pharm Sci 2011;1:98-106.

15. Hetal S, Disha P, Mahendra V. Evaluation of conventional and serological methods for rapid diagnosis of cryptococcal meningitis in HIV seropositive patients at tertiary care hospital. Natl J Community Med 2011;3:354-7.

16. Sharma R, Das A, Duggal N, Hans C. Cryptococcal meningitis in an immunocompetent patient. Sch J Med 2014;6:414-6.

17. Lungran P, Devi AV, Singh WS, Damroulien S, Mate H, Golmei A. Cryptococcosis: Its prevalence and clinical presentation among HIV positive and negative patients in Rims, Manipur. IOSR J Dent Med Sci 2014; $13: 38-41$.

18. Dulaimi HA, Shafiq SA. Use of the fruits of some plants to prepare media cultures to isolate and diagnose the yeast of Cryptococcus neoformans. J Mustansiriya Sci 2011;1:251-62.

19. Minhas N, Patil S, Sharma PC. Novel preparation of culture media for cultivation of Cryptococcus neoformans with extracts of different plant products. Int J Pharm Sci Rev Res 2013;24:70-5.
20. Katiyar R, Deorukhkar SC, Saini S. Comparison of different media for the pigment production of $C$. neoformans. J Clin Diagn Res 2011;5:1187-9.

21. Ajah HA. New culture medium, fava bean (Vicia faba)agar for cultivation and identification of $C$. neoformans. Int $\mathrm{J}$ Adv Res 2015;3:964-71.

22. Ughari JH, Elmahmood AM, Mazara S. Studies on the antibacterial activity of root extracts of Carica papaya L. Afr J Microbiol Res 2007:7:37-41.

23. Kareem RA. Effect of Organic Solvents and Secondary Compounds of Dodi Leaves and Flowers in Some Aspects of Culex Mosquito Thesis. Faculty of Science University of Qadisiyah; 2016

24. Silverstein R, Webster F, Kiemle D. Spectrometric Identification of Organic Compounds. $7^{\text {th }}$ ed. USA: John Wiley and Sons; 2005.

25. Mohammad NS, Srinivasulu A, Chittibabu B, Rao VU. Isolation and purification of antibacterial principle from Avicennia Marina L in methanol. Int J Pharm Pharma Sci 2015;7:38-41.

26. Han AR, Kim HY, So Y, Nam B, Lee IS, Nam JW, et al. Quantification of antioxidant phenolic compounds in a new Chrysanthemum cultivar by high-performance liquid chromatography with diode array detection and electrospray ionization mass spectrometry. Int $\mathrm{J}$ Anal Chem 2017;2017:1254721.

27. Sheikh RE, Amin AS, Atwa MA, Gouda AA, Abdullah AA. Determination of phenolic components and antioxidant activity of some Egyptian tea samples. Int J Pharm Pharm Sci 2015;7:198-202. 